\title{
Studies on Different Breeding Systems in Nerium Cultivars (Nerium oleander L.)
}

\author{
M. Parashuram ${ }^{*}$, K.R. Rajadurai ${ }^{2}$, S. Haripriya ${ }^{3}$ and A John Joel ${ }^{4}$ \\ ${ }^{1}$ Department of Floriculture and Landscaping, ${ }^{3}$ Department of Nano Science and Technology, \\ Horticulture College and Research Institute, TNAU Coimbatore-641003, Tamil Nadu, India \\ ${ }^{2}$ Department of Floriculture and Landscaping RRS, Aruppukottai, India \\ ${ }^{4}$ Centre for Plant Breeding and Genetics, TNAU Coimbatore-641003, Tamil Nadu, India \\ *Corresponding author
}

\begin{tabular}{|c|}
\hline Keywords \\
\hline $\begin{array}{l}\text { Autogamy, } \\
\text { Geitonogamy, } \\
\text { Controlled pollination, } \\
\text { Seed viability and } \\
\text { Seed germination }\end{array}$ \\
\hline Article Info \\
\hline $\begin{array}{l}\text { Accepted: } \\
12 \text { September } 2018 \\
\text { Available Online: } \\
10 \text { October } 2018\end{array}$ \\
\hline
\end{tabular}

\section{Introduction}

Nerium (Nerium oleander L.) is an evergreen shrub or small tree in the dogbane family Apocynacea (Kiran and Prasad, 2014; Yadav et al., 2013). The Apocynacea is a diverse and

\begin{abstract}
A B S T R A C T
The objective of this work was to study the different breeding systems, seed viability and seed germination in four nerium Cultivars (Nerium oleander L.). Different breeding systems like natural open pollination, autogamy, controlled pollinations and geitenogamy were studied in two seasons. In both the season of pollination no fruit set was observed in autogamy. In case of natural open pollination both the season of pollination up to five per cent of fruit set was observed in nerium cultivars. During first season of controlled pollination, intra varietal crosses maximum fruit set was observed in Pink cultivar and minimum fruit set was observed in Yellow cultivar. In second season of controlled pollination, among the different cross combination maximum fruit set was observed in Pink X White combination of crosses followed by Pink X Red combination of crosses and the minimum fruit set was observed in Yellow $\mathrm{X}$ Pink combinations of crosses respectively. In case of geitonogamy Pink cultivar showed maximum fruit set per cent, followed by White cultivar and least in Red cultivar. Regarding seed viability, Pink cultivar showed maximum seed viability and followed by Red cultivar and least in White cultivar. In seed germination test, maximum seed germination per cent was in pink cultivar in both nursery media and paper towel method and least in Yellow cultivar in nursery media method and Red cultivar in paper towel method. The results obtained from studies of the different breeding system can aid in planning crosses and establishment of nerium hybridization programs using compatible cultivars.
\end{abstract}

species rich family in the order Gentianales. The family has a widespread distribution throughout tropical and temperate regions (Barrios and Koptur, 2011). Nerium oleander L. is widely cultivated that no precise region of origin has been identified, though South 
West Asia has been suggested. It typically occurs around dry stream beds. In India nerium distributed throughout the country but commercial cultivation takes place in Tamil Nadu only. Nerium grows to 2-6 m tall, with erect stems that spread outward as they mature. Leaves are 10 to $22 \mathrm{~cm}$. long, narrow, acute and have a prominent mid rib, are "leathery" in texture and usually arise in groups of three from the stem. The plant produces terminal flower heads, usually pink or white (Kiran and Prasad, 2014). Neriumis an ornamental plant used in the urban landscaping due to its spectacular flowering which can have different colorations as the variety and its resistance to long drought periods (Albornoz et al., 2014).

In Tamil Nadu, nerium is used for various purposes like ornamental plants in garden, religious purpose and garlands. Now days in India neruim cultivation gaining more importance due to its wide utility but no systematic research has been carried out. Hence keeping all these in view, the research has been undertaken toStudy the different breeding systems innerium cultivars which will help for further crop improvement programme through hybridization.

\section{Materials and Methods}

The study was conducted during 2016-2017 to study the different breeding systems in nerium cultivars at the Department of Floriculture and Landscaping, Horticulture College and Research Institute, Tamil Nadu Agricultural University, Coimbatore. The four cultivars of nerium was collected from different districts of Tamil Nadu. The well-established ground layered plants were used for plating. In a fortnight duration, all the plants were established well. Flower initiation occurred two months after planting and all the flowers were nipped off regularly until the plants were reaches four month old.
The study was conducted in two seasons. First season pollination was carried out in the month of October and November 2016. For second season, pollination was carried out in the month of December 2016 and January 2017. In first season of pollination, natural open pollination, autogamy, controlled pollinations were followed. In second season of pollination, natural open pollination, autogamy, geitenogamy and controlled pollination were followed figure 1 and 3 . The autogamy was carried out to know the selfcompatibility in nerium cultivars. For the artificial cross pollination in nerium cultivars crossed with all possible combinations. The total of twelve cross combinations were followed are Red X White, Red X Pink, Red X Yellow, White X Red, White X Pink, White X Yellow, Pink X Red, Pink X White, Pink X Yellow, Yellow X Red, Yellow X White and Yellow X Pink.

\section{Natural open pollination}

Natural open pollination was carried out by tagging the selected buds and allowed for natural open pollination. The fruit set percentage was observed at 25 days after tagging.

\section{Autogamy}

Autogamy (Self-pollination) was carried out by covering the selected mature bud with the butter paper cover. The fruit set was observed at 25 days after the covering with butter paper caver.

\section{Geitonogamy}

Geitonogamy (Artificial self-pollination) was carried out on fully developed flower buds in each cultivar. The fully developed flower buds was bagged to prevent the entry of foreign pollen grains. The fresh pollen grains of bagged flowers were dusted on the stigmatic 
surface of same flower on the day of anthesis. After pollination the flowers were bagged with butter paper cover. The fruit set percentage was observed after $25^{\text {th }}$ day of pollination.

\section{Controlled pollination}

Controlled pollination (Artificial cross pollination or hand pollination) was carried out by selecting the flower bud that will open next day. The selected buds ware emasculated in the evening and bagged as female parent. Next day morning the emasculated flowers ware pollinated using the pollens from the desirable male parent. Artificial pollination was carried out during morning hours between 6am to $9 \mathrm{am}$.

After crossing the flowers ware bagged and labelled for recording the fruit set percentage figure 2. The observations were recorded are fruit set percent, number seeds per fruit, seed viability and seed germination percent.

The number of fruit set in different pollination was recorded and percentage of fruit set was assessed against the number of flowers pollinated. Number of seeds per fruit was calculated by taking mean of number of seeds per 15 fruits in each cultivar.

\section{Seed viability}

Seeds were pre conditioned by soaking the seeds in water for 24 hours. The embryos were separated from the seeds by pressing the seeds or with the help of needles. The separated embryos was soaked in 1\% 2, 3, 5 - triphenyl tetrazolium chloride for the 24 hours. Then the viability of seed was observed, based on red colour formation and the viability per cent was estimated by adapting the following formula.

Number of seeds fully stained Seed viability $(\%)=$---------------------- X 100 Total number of seeds placed

\section{Seed germination}

Seed germination was carried out by following two methods $i$. e., though nursery media and paper-towel method.

\section{Seed germination test though nursery media}

Nursery media was filled in the plastic trays and seed was sown in the media.

Then the trays were irrigated and kept in germination room under controlled condition $\left(25^{\circ} \mathrm{C}\right.$ and $90 \%$ humidity). Every alternate day, watering was given until the seed germination was completed.

Seed germination was observed 30 days after sowing and germinated seedlings were counted mean value was calculated, expressed in percentage $(\%)$.

Seed germination percent was calculated by using the formula

Number of seeds germinated

Germination $(\%)=$ X 100

Total number of seeds sown

\section{Seed germination test in paper-towel method}

After soaking the paper towel in water, the seeds are placed in two layers of 25 numbers across the capillary direction above the paper. Then another wet paper towel were placed above and rolled. Then the paper roll was kept in germination room under controlled condition $\left(25^{\circ} \mathrm{C}\right.$ and $90 \%$ humidity).

The seed germination was observe after 30 days and germinated seeds was counted, mean value was calculated and expressed in percentage $(\%)$. 


\section{Results and Discussion}

Studies on breeding systems are essential in crop improvement through hybridization programme. Knowledge on fruit set percentage in different pollination methods will help full to indicating the berries in hybridization programme. Neruim oleander (L.) is self-compatible, but need the insect to visit the flower for fruit set. The crop fundamental information on fruit set percentage, seed viability and seed germination etc., are much needed for programming crop improvement through hybridization.

Data pertaining to the fruit set performance of different nerium cultivars for first season pollination are presented in table 1 . In natural open pollination, highest fruit set per cent was observed in Pink cultivar $(5.00 \%)$ and no fruit set was found in Yellow cultivar. The Red and White cultivars shown on par result $(2.50 \%)$. There was no fruit set occurred in Autogamy in all the nerium cultivars. In case of controlled pollination highest fruit set $(92.5 \%)$ was recorded in Pink cultivar followed by White cultivar $(90.00 \%)$ and the minimum fruit set was observed in Yellow cultivar (77.50 \%). The automatic selfing was prevented by spatial separation of anther and stigma and pollinators are thus necessary for reproduction in nerium. If unvisited, neriumflowers do not set fruit, as demonstrated by lack of fruiting in inflorescences bagged to exclude pollinators. Flowers left exposed for natural pollination, on the other hand, only rarely set fruit. If hand pollinated, however, the probability that a flower will set a fruit increases dramatically Herrera (1991).

Data pertaining to the fruit set performance of different nerium cultivars for second season pollination presented in table 2 and 3 . Highest fruit set per cent in natural open pollination was observed in White cultivars $(5 \%)$ and no fruit set was recorded in Yellow cultivar. Pink and Red cultivars shown on par result $(2.5 \%)$. In case of autogamy there was no fruit set recorded in nerium cultivars. The Pink cultivar showed the highest per cent fruit set (57\%) in geitonogamy followed by White cultivar $(52.00 \%)$ and the least fruit set was observed in Red cultivar (49 \%). Herrera (1991) in Nerium oleander (L.) reported similar results in artificial self-pollination studies.

In present study, controlled pollination was studies with all possible combination of crosses maximum fruit set per cent (68.00) was noticed when White is used as pollen parent with Pink followed by Red is used as pollen parent with Pink (67.00). Thus Pink is serve as best female parent with other cultivars in hybridization programme. This is in agreement with observation Herrera (1991). In Glorious superba, maximum pod set was observed in artificial cross pollination within the species followed by self-pollination. Minimum pod set was noticed in natural selfpollination (Anandhi and Rajamani, 2012). Low fruit set per cent was noticed under open pollination is not a rarity, such condition is quite common in many tropical trees.

A low fruit set per cent is normally an indication of pollinator limitation in Rauvolfia serpentine (Usman et al., 2016). In Stapeliagigantea, fruit set and seed set via natural pollination were significantly lower than via hand cross-pollination (Herrera and Nasar, 2009). The artificial cross pollination through xenogamy enhanced the rate of fruit set in Rauvolfia micrantha (Kulloli and Shreekala, 2009).

The results pertaining to mean per cent seed viability and seed germination are presented in table 4. 


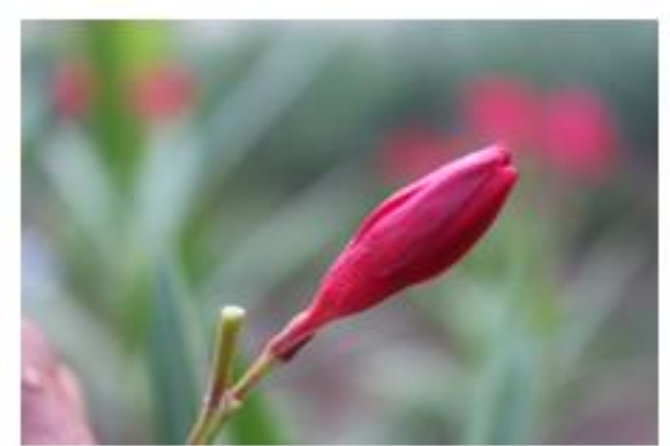

Selection of mature bud for pollination

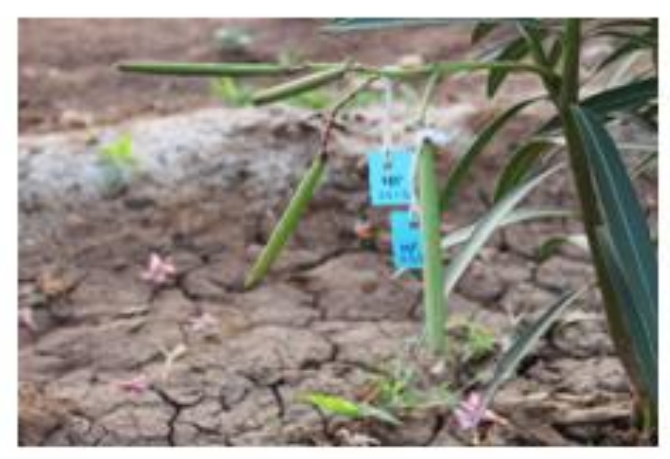

Fruit set

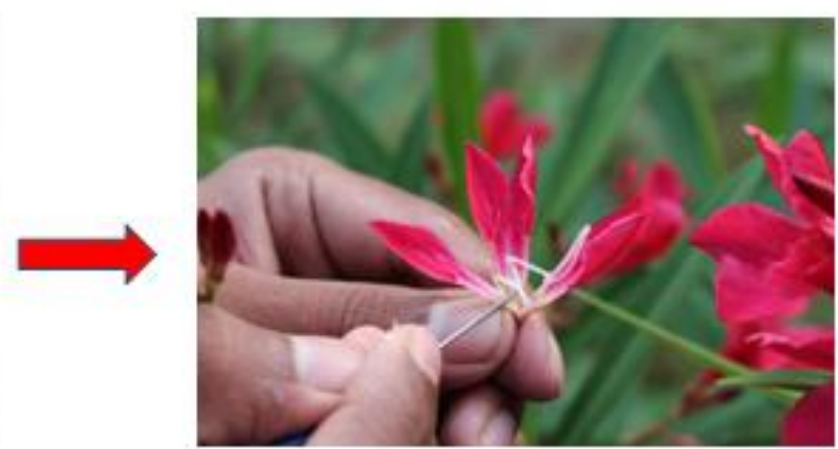

Emasculation

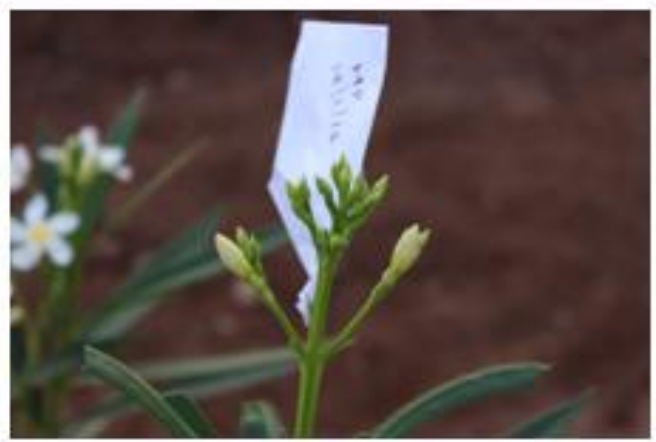

Bagging and tagging of pollinated stigma

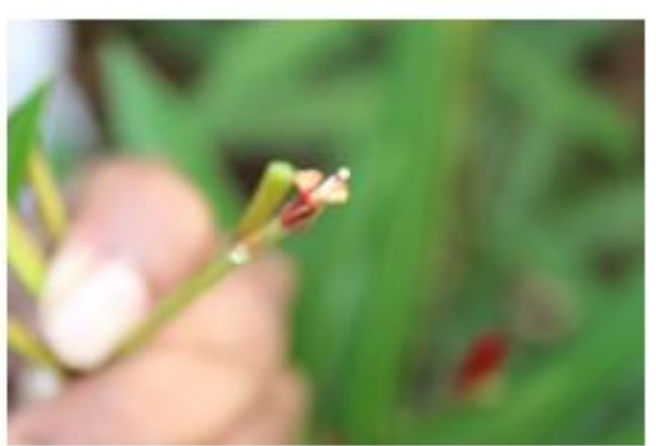

Emasculated flower ready for pollination

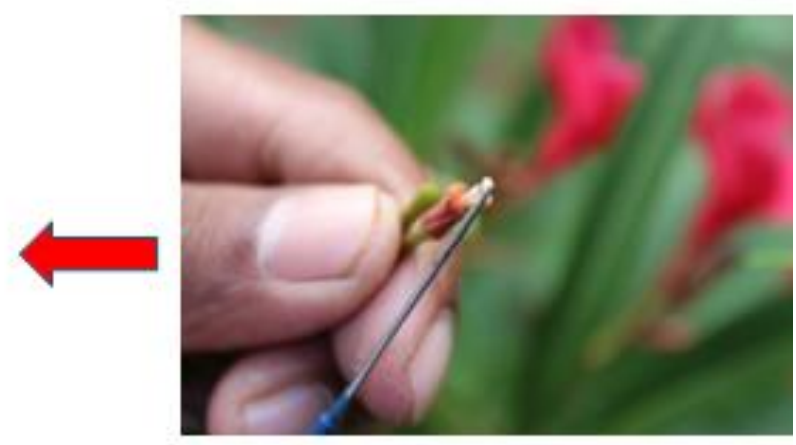

Dusting of pollen grains on the stigmatic surface

Fig.1 Steps followed in controlled pollination 

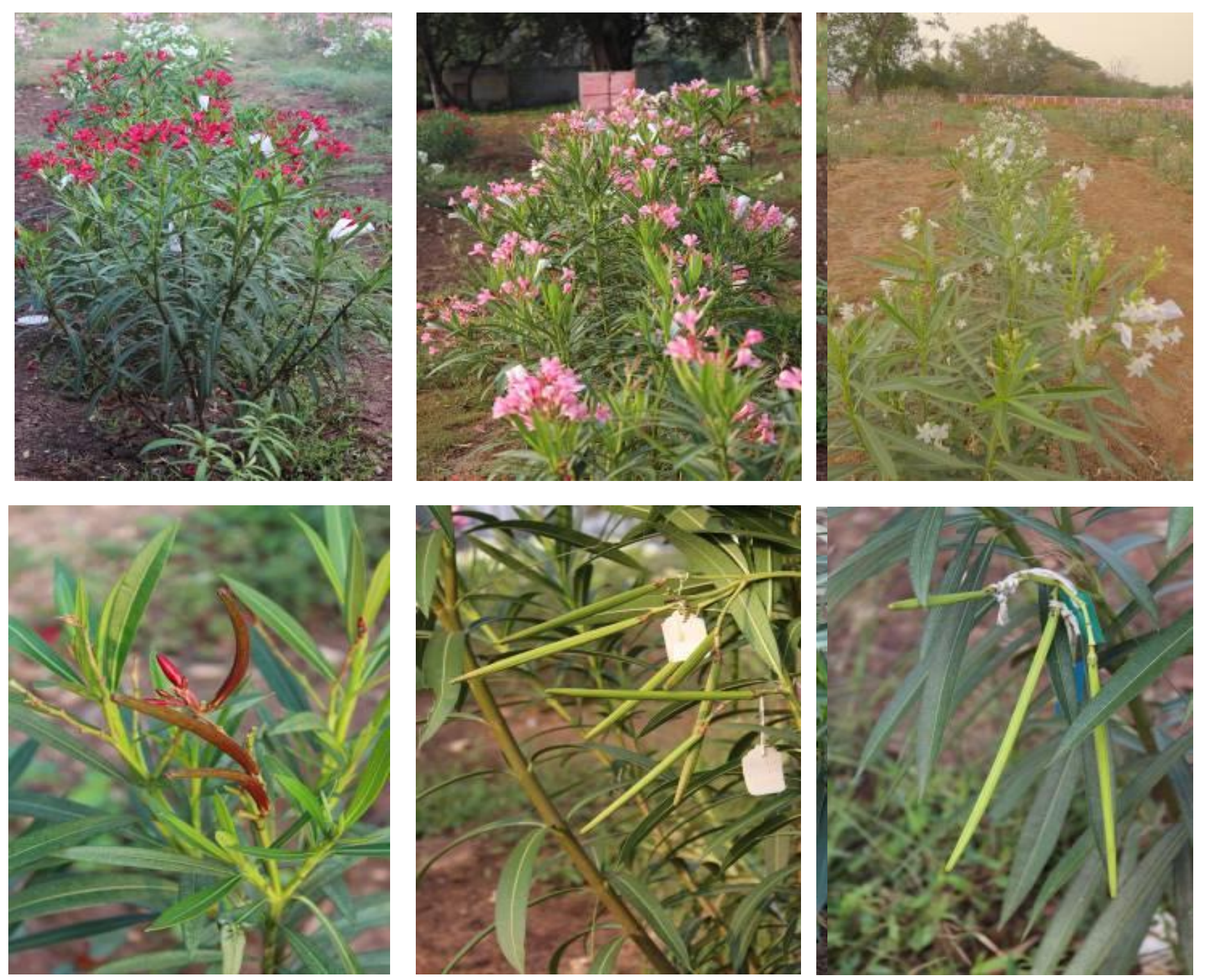

Fig: 2 Crossing block and fruit setting in Red, Pink, White and yellow cultivars respectively 
Fig.3 General view of nerium field

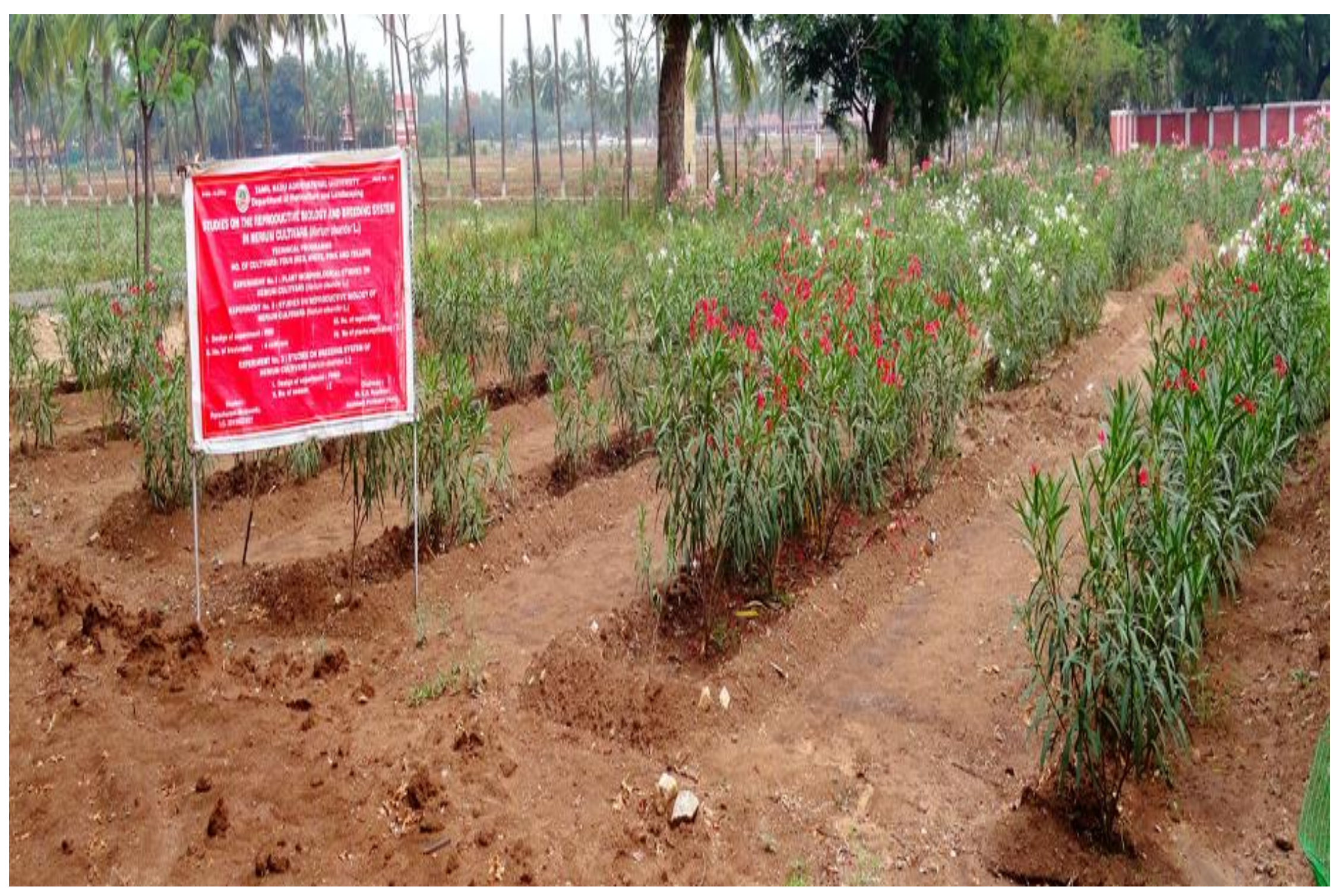


Int.J.Curr.Microbiol.App.Sci (2018) 7(10): 1625-1634 
Table.1 Fruit set percentage in first season pollination of nerium (Nerium oleander L.) cultivars

\begin{tabular}{|l|c|c|c|c|}
\hline Cultivar & $\begin{array}{c}\text { Number of } \\
\text { flowers }\end{array}$ & Natural open pollination & Autogamy & $\begin{array}{c}\text { Controlled } \\
\text { pollination }\end{array}$ \\
\cline { 3 - 5 } & 40 & 2.5 & 0 & 85.00 \\
\hline Red & 40 & 2.5 & 0 & 90.00 \\
\hline White & 40 & 5.00 & 0 & 92.50 \\
\hline Pink & 40 & 0 & 0 & 77.50 \\
\hline
\end{tabular}

Table.2 Fruit set percentage in second season pollination of nerium (Nerium oleander L.) cultivars

\begin{tabular}{|c|c|c|c|c|}
\hline Cultivars & $\begin{array}{c}\text { Number of } \\
\text { flower }\end{array}$ & Natural open pollination & Autogamy & Geitonogamy \\
\hline Red & 100 & 2.5 & 0 & 49.00 \\
\hline White & 100 & 5.0 & 0 & 52.00 \\
\hline Pink & 100 & 2.5 & 0 & 57.00 \\
\hline Yellow & 100 & 0 & 0 & 51.00 \\
\hline
\end{tabular}

Table.3 Fruit set percentage in controlled pollination in different combinations of crosses in nerium (Nerium oleander L.) cultivars

\begin{tabular}{|c|}
\hline Combination of crosses \\
\hline RXW \\
\hline RXP \\
\hline RXY \\
\hline WXR \\
\hline WXP \\
\hline WXY \\
\hline PXR \\
\hline PXW \\
\hline PXY \\
\hline YXR \\
\hline YXW \\
\hline YXP
\end{tabular}

\begin{tabular}{|c|c|}
\hline $\begin{array}{c}\text { Number of flowers } \\
\text { crossed }\end{array}$ & $\begin{array}{c}\text { Fruit Set }(\%) \\
\text { Controlled pollination }\end{array}$ \\
\hline 35 & 60.00 \\
\hline 35 & 62.85 \\
\hline 35 & 57.14 \\
\hline 60 & 63.33 \\
\hline 60 & 60.00 \\
\hline 60 & 58.33 \\
\hline 100 & 67.00 \\
\hline 100 & 68.00 \\
\hline 100 & 64.00 \\
\hline 25 & 56.00 \\
\hline 25 & 52.00 \\
\hline 25 & 52.00 \\
\hline
\end{tabular}

Table.4 Seed viability and seed germination in nerium (Nerium oleander L.) cultivars

\begin{tabular}{|c|c|c|c|c|}
\hline \multirow{2}{*}{ S. No } & Cultivars & Seed viability (\%) & \multicolumn{2}{|c|}{ Seed germination (\%) } \\
\cline { 3 - 5 } & & & Nursery media & Paper \\
\hline $\mathbf{1}$ & Red & 90.63 & 26.45 & 51.32 \\
\hline $\mathbf{2}$ & White & 87.15 & 23.34 & 54.55 \\
\hline $\mathbf{3}$ & Pink & 94.20 & 35.25 & 61.36 \\
\hline $\mathbf{4}$ & Yellow & 88.67 & 21.41 & 51.86 \\
\hline
\end{tabular}


Highest seed viability was found in Pink cultivar $(94.20 \%)$ and followed by Red cultivars $(90.63 \%)$ and the minimum was observed white cultivar $(87.15 \%)$ regarding seed germination nursery media method, highest per cent of seed germination $(35.25 \%)$ was observed in Pink cultivar followed by Red cultivar $(26.45 \%)$ and the minimum in Yellow cultivar $(21.41 \%)$. In paper towel method highest per cent of seed germination $(61.36 \%)$ was recorded in Pink cultivar followed by White cultivars $(54.55 \%)$ and the lowest in Red cultivar (51.32). Seed germination studies in $N$. oleander L. revealed that seeds will starts to germinate after two weak of sowing and continues up to one month.

Maximum seed germination was found in paper towel method than the nursery media in all the cultivars studied. Seed germination per cent was higher in paper towel method because of more moisture content throughout the period of seed germination. This was in accordance with reports of Herrera (1991) that Nerium oleander L. seeds germinate well when placed on a wet substrate, but do so faster if placed directly on water where they can float for months. Kulloli and Shreekala (2009) in Rauvolfia micrantha stated that seed germination percentage in natural habitat was approx. $30 \%$.

Similar observation was made by Herrera and Nassar (2009) in Stapeliagigantea. Nerium cultivars showed no fruit set in autogamy, thus pollinators are necessary to fruit set in nerium cultivars. Even though self and cross compatibility was observed in nerium cultivars but per cent fruit set was maximum in cross pollinations. There was no seed dormancy was observed and seed germinates within a month. Hence, in coming day's crop improvement thorough hybridization in nerium cultivars can be taken up.

\section{References}

Albornoz, A, Fernandez M, Vilchez J, Fernandez C and Martinez L. 2014. Effect of paclobutrazol on growth oleander (Nerium oleander L.) plant in nursery. Rev. Fac. Agron, Supl 1: 301311.

Anandhi, S and Rajamani K. 2012. Reproductive biology of Gloriosasuperba. Open Access J. of Medicinal and Aromatic Plants 3 (2): 511.

Barrios B and Koptur S. 2011. Floral biology and breeding system of Angadeniaberteroi (apocynaceae): Why do flowers of the pineland golden Trumpet produce few fruits? Int. J. Plant Sci 172(3):378-385.

Herrera I and Nassar J M. 2009. Reproductive and recruitment traits as indicators of the invasive potential of Kalanchoedaigremontiana (Crassulaceae) and Stapeliagigantea (Apocynaceae) in a Neotropical arid zone. Journal of Arid Environments 73: 978-986.

Herrera J. 1991. The reproductive biology of a riparian Mediterranean shrub, Nerium oleander L. (Apocynaceae). Botanical journal of the Linnean Society 106:147-172.

Kiran, C. And D. N. Prasad. 2014. A Review on: Nerium oleander Linn. (Kaner). IJPPR 6(3): 593-597

Kulloli S K and Sreekala A K. 2009. Pollination Ecology of Rauvolfiamicrantha Hook. F. (Apocynaceae): A Critically Endangered Medicinal Plant from the Southern Western Ghats. Phytomorphology 3 (4): 96-101.

Usman G, Mandal A K, Chawaan P H and Mishra Y. 2016. Reproductive biology and breeding system in Rauvolfia 
serpentine (L.) Benth. Ex Kurz. Ind J Plant Physiol 21(1):31-36.

Yadav D P, Bharadwaj N P S, Yedukondalu $M$ and Ravi Kumar A. 2013. Phytochemical evaluation of
Nyctanthesarbortristis, Nerium oleander and Catharathnus roseus. Indian Journal of Research in Pharmacy and Biotechnology. 1(3): 133- 137

\section{How to cite this article:}

Parashuram, M., K.R. Rajadurai, S. Haripriya and John Joel, A. 2018. Studies on Different Breeding Systems in Nerium Cultivars (Nerium oleander L.). Int.J.Curr.Microbiol.App.Sci. 7(10): 1625-1634. doi: https://doi.org/10.20546/ijcmas.2018.710.184 